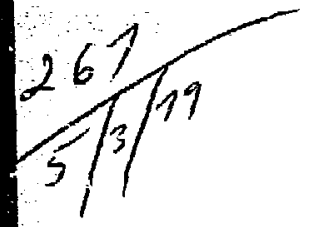

\author{
HAthes \\ APRIL 1979
}

16.2536

PPPL-1534

DC-20a, d, f

\title{
THE EFFECT OF CURRENT PROFILE EVOLUTION ON PLASMA-LIMITER INTERACTION AND THE ENERGY CONFINEMENT TIME
}

\section{PLASMA PHYSICS LABORATORY}

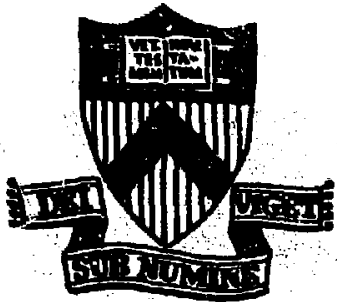

DISTRIBUT

\section{PRINCETON UNIVERSITY PRINCETON, NEW JERSEY}

This work wa supported by the $0 ., S$, pepartment of Bnergy Dontract No. EY-76-C-02-3073. Reproduct 1on, translat lon, publication, use and dipposal, tn thole or in part, by or For the dalted states Government is permitted. 
THE EFFECT OF CURRENT PROFTLE EVOLUTION CN

PLASMA-LIMITER INTERACTION AND THE

ENERGY CONE INEMENT TIME

R. J. Hawryluk, K. Bol, N. Bretz, D. Dimock, D. Eames, E. Hinnov, J. Hosea, II. Hsuan, F. C. Jobes, D. Johnson, E. Meservey, N. Sauthoff, G. L. Schmidt, S. Suckewer, M. Ulrickson and $S$. von Goeler

Plasma physics Laboratory, Prinseton University

Princeton, New Jersey USA 08544

ABSTRACT

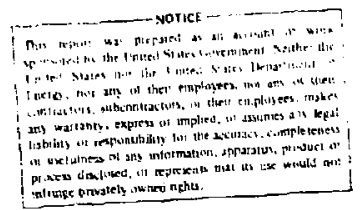

Experiments conducted on the PIT tokamak have shown that both plasina-limiter interaction and the gross energy confinement time are functions of the gas influx during the discharge. By suitably controlling the gas influx, it is possible to contract the current channel, decrease impurity radiation from the core of the discharge, and increase the gross energy confinement time, whether the aperture limiters were of tungsten, stainless steel or carbon. 


\section{INTRODUCTION}

It is well known (see for instance, Refs. [1-8]) that the gross energy replacement time and temperature of a tokamak discharge are affected by such macroscopic parameters as plasma density, toroidal field, plasma current, major and minor radius, wall conditions, limiter material (hence impurity content), and radial equilibrium. However, for the same values of the macroscopic parameters, variations greater than a factor of 2 in the gross energy replacement time and in the temperature of the discharge are quite common. Experiments on PLT indicate that in addition to controlling the macroscopic parameters of the discharge, it is important to control the manner in which the discharge evolves to the guasi-steady state. The mode of evolution is important in determining impurity levels and radiation losses, the current density profile and the MHD stability in the quasi-steady state. These quantities in turn are crucial in determining both the energy confinement time and temperature of the discharge. [7]

In PLT, changes in the initial filling pressure and the gas inElux modify the evolution of the startup phase of the discharge with effects which persist throughout the quasi-steady state. Typically, the duration of the startup phase - i.e., the time required for the current to increase and the current profile to relax - is 100-200 msec and the duration of the quasi-steady state is ¿00-500 msec. The duration of quasi-steady state is long compared. with the energy and particle replacement times, but comparable with the neoclassical current relaxation time. However, the observed current relaxation time during the startup paase is often short compared with the neoclassical current penetration time . Qual itatively, it appears that with appropriate ajjustment of the gas influx during the 
startup phase, the energy balance in the plasma periphery is modified in such a way as to establish very early in the evolution of the discharge a peakea instead of a hollow temperature profile which persists during the quasi-steady pliase of the discharge. The relatively low edge temperature associated with the peaked profile leads to reduced plasma limiter interaction $[9,10]$ in the startup phase, and to lower concentrations of l.jmiter material in the plasma. Most important, the enerfy confinement is improved beyond the gain anticipated from the reduced radiation loss.

In analyzing tokamak plasmas, it is exceedingly difficult to distinguish cause from effect, not only because of our limited ablility to vary plasma paraineters independently but even more because temperature and current density profiles, impurity conditions, energy transport, and plasma instabilities interact strongly. Nevertheless, the effect of differences in discharge evolution on the subsequent plasma parameters of the quasi-steaày state is, in our experience, great enough to warrant a preliminary report. Furthermore, in tokamaks larger than PLT, the problem of how best to establish the discharge for optimum results is likely to become even more difficult.

In this paper, experiments illustrating the importance of controlling the evolution of the discharge are described. The bearing of current evolution effects on plasma-limiter interaction is discussed in section 2 , and on energy confinement in Section 3 .

\section{PLASMA-LIMITER INTERACTION}

In PLT, four tungsten rail limiters were used originally to 
define the plasma minor radius. After extensive low power (Taylor [11]) discharge cleaning, tungsten impurities in high power deuterium discharges radiated a large fraction of the ormic input power from tine plasma core. $[8,12,13]$ The intensity of the tungsten radiation was correlated directly with the ion temperature in the edge region and inversely with the concentration of low $z$ impurities. [9] Subsequent experiments with a carbon limiter demonstrated that the liniters and not the wall were the important, if not the sole source of tungsten; thus high levels of tungsten radiation are an indication of adverse plasma-limiter interaction. With a large influx of helium or deliterium gas, and the systematic use of titanium yettering between discharges, the tungsten radiation from the core could be reduced to a negligible level of less than $0.15 \mathrm{~W} / \mathrm{cm}^{3}$. $[8,12]$ In hydrogen or deuterium discharges without gettering, it was impossible to sustajn throughout the discharge an influx of gas sufficient to simultaneously keep the tungsten radiation at a negligible level throughout the pulse and avoid a discuption. [8,12] Nonetheless, in these discharges the tungsten radiation cou'd still be reduced, either deliberately by increasing the filling pressure and the gas influx, or spontanecusly in discharges following a major disruption in which a greater influx of gas and perhaps of low $\mathrm{z}$ impurities increased the density and contracted the current channel during the startup phase.

In Fig. 1, two hydrogen discharges are compared with different initial filling pressures and gas influx rates. The tungsten radiation was monitored by an ultra-soft $x$-ray detector which is sensitive to wavelengths less than about $150 \AA$. [14] In discharges with a substantial concentration of tungsten and low concentrations of oxygen and carbon, the radiation detected by the ultra-soft $x-r a y$ 
detector was in good agreement with vacuum ultraviolet measurements of the tungsten radiation in the band 30 to $70 \AA$. [15] In the dis charge labeled (b) the initial filling pressure and the influx of gas were increased compared with the discharge labeled (a). This resulted in a substantial reduction in the ultra-soft $x-r a y$ signal, an increase in the line average electron density, a contraction of the current channe]. and a reduction in the quasi-steady state loop voltage. The current profile was monitored by measuring $\ell_{i} / 2+\beta_{\theta}$ ' which is determined from the plasma position and the current in the vertical field coils used to maintain radial equilibrium. The dimensionless internal inductance, $\ell_{i}$, is that defined by shafranov [16], and $\beta_{\theta}$ is the usual poloidal beta. Typically $\beta_{\theta}$ is small (< 0.2$)$ during the startup phase, so that the $l_{i} / 2+\beta_{\theta}$ measurement is a good monitor of the gross current profile shi ge. The higher internal indictance of (b) which results from the constriction of the current channel, causes the plasma current to rise more slowly in (b) than in (a) for a fixed primary current. The differences in evoluticn of the plasma current, internal inductance and tungsten radiation shown in Fig. 1 are quite general and have been observed in experiments with various limiters, working gases and types of wall conaitioning.

The strong dependence of the intensity of the tungsten radiation on the shape of the curxent profile is shown in Fig. 2 for a series of hydrogen discharges produced after extensive low power discharge cleaning. Both tungsten radiation and the equilibrium parameter $\ell_{i} / 2+\beta_{\theta}$ were evaluated at $t=70 \mathrm{msec}$. Clearly the value of the internal inductance during the startup phase is a good indicator of the plasma-limiter interaction. The data shown by Fig. 2 include results from discharges with different initial filling pressures 
and gas influx rates, diffe ent initial currents in the ohmic heating coil (which also influences the evolution of the discharge), and differences in the wall condition following a disruption. Some of the scatter in the data shown in Fig. 2 can be attributed to differences in the evolution of the current profile. In order to minimize the tungsten radiation, it appears to be desirable to contract the current profile throughout the startup phase - not merely at $70 \mathrm{msec}$.

In order to constrict the current channel and reduce the tungsten radiation without causing a disruption, some control of the wall conditions and very precise control of the gas j.nflux is required. As shown in $\mathrm{Fig} .3$, the transition from broad to peaked profiles and the corresponding decrease in tungsten radiation was accompanied by only a $10 \%$ increase in the density, measured at $t=70 \mathrm{msec}$. A further increase in the flow rate resulted in a major current disruption.

Figures 2 and 3 taken together imply an inverse relation between the density during the startup phase of the discharge and the sub"sequent tungsten level in the plasma. However, the density at which the transition from broad to peaked current profiles occurs depends upon many factors. It is a function of both the method of wall conditioning (e.g. discharge cleaning, titanium gettering), conditions which bear on the level of light impurities in the discharge, particularly oxygen, as well as of the applied single-turn voltage, which is determined by the primary current. Consequently, compared to the 
shape of the current profile as. measured by $l_{i}$, the density is a relatively poor predictor of plasma-limiter interaction. A dependence of the plasma-limiter interaction on the shape of the current profile can be qualitatively understood in the following way. If the current profile is broad (an occurrence sometimes accompanied by a hollow temperature profile), the edge temperature is relatively high, resultino in increased plasma-limiter interaction. Thus, peaked profiles are desirable. However if the current channel is too constricted, the discharge is more susceptible to disruptions.

Differences in the tungsten concentrations might be a result of a change in the impurity confinement time as opposed to a change in the plasma-limiter interaction, as implied above. This point has been checked to some extent by monitoring the heat deposited on a carbon limiter. However, it should be noted that there is no evidence to suggest that in a normal discharge the heat flux to either the tungsten or the carbon limiters is sufficient to cause evaporation. Thus, though the heat deposited on the limiter is a direct measure of plasma-limiter interaction, it is an indirect monitor of the factors responsible for impurity influx. During 1977, a carbon limiter which was rot water cooled was installed in addition to the tungsten limiters. Figure 4 shows the net temperature rise on this carbon limiter (heat deposited during the pulse less the radiation and conduction loss between pulses) versus current profile shape evaluated at $50 \mathrm{msec}$ during the startup phase. The strong inverse correlation suggests that the reduction in impurities observed with a contracted ourrent: 
channel must be at least partly due to reduced plasma-limiter interaction.

\section{GROSS - ENERGY REPLACEMENT TIME}

In the past year (1978), several important modifications in machine operation were made. These changes have been discussed in Ref. [8] and will only be briefly described here. The tungsten limiters were replaced with stainless steel limiters (inside; outside, top and bottom) and two water cooled carbon limiters (top and bottom), and titaniun: gettering of vacuum vessel walls between discharges came into routine use. $[17,18]$ The effect of these changes has been to eliminate tungsten radiation and through the use of titanium gettering to increase the maximum line dverage density in $\mathrm{H}^{+}$or $\mathrm{D}^{+}$ discharges from 5 to $10 \times 10^{13} \mathrm{~cm}^{-3}$.

In addition to these major changes, a gas feedback system (Fig. 5) was ilst:alled to control the evolution of the discharge during the startup phase and compensate for changes in wall conditions. Preprogrammed density, $\bar{n}_{e}$ and $\overline{l_{i} / 2+\bar{\beta}_{\theta}}$ signals are constructed and the difference between the measured and the desired waveforms is used to arive a pulse gas valve (Veeco $\mathrm{pV}-10$ ). The valve is mounted directly on the vacuum vessel wall to minimize the response time of the system ( 5 msec). Figure 5 illustrates the use of the gas feedback system for both high and low density discharges. This system has made it possible to make parameter scans more easily and to evaluate differences due to changes in the startup phase, though it does not change the operating range imposed by plasma disruptions. 
In recent parameter scans of deuterium discharges with both stainless steel and carbon limiters as well as in earlier high density helium discharges $\left(\bar{n}_{e} \leqslant 1 \times 10^{14} \mathrm{~cm}^{-3}\right)$ with tungsten Iimiters, [12] substantial variations, in the electron energy replacement time (factor of 2) are observed for the same macroscopis plasma parameters. These variations are considerably greater than the uncertainties in the measurement. It appears that these variationscan be attributed to the manner in which the discharge evolves and to changes in the plasma periphery due to differences in the gas influx. Furthermore, it appears that these variations can be controiled.

Two different experiments were conducted to examine the effect of the gas influx on the energy replacement time. Tine first set of experiments compares the effect of contracting the current profile using the gas feedback system (see 3.1). The second set of experiments illustrate that favorable results can also be obtained during the quasi-steady state by applying a short but intense burst of gas (see 3.2). Both of these experiments were condicted with'stainless steel limitexs, titanium gettering between discharges and deuterium as the working gas.

3.1 Contracting the current profile using the gas feedback system

Two discharges will be compared having very similar values of line-average density. plasma current and toroidal field. In the first (conducted on October 16, 1978) the gas feedback system was controlled with the density input, and in the second (conducted october 24,1978 ) with both density and $\ell_{i} / 2+\beta_{\theta}$ irput. In the second case the preprogrammed waveforms were constructed to result in the most 
contracted current profile possible without disruptions during the startup phase. The evolution of the density and $\ell_{i} / 2+\beta_{\theta}$ waveforms is shown in Fig. 6. When the current profile was not deliberately contracted, the temperature profiles measured with the multi-channel Thomson scattering [19] system were initially hollow and only became peaked some $300 \mathrm{msec}$ into the discharge. In cuntrast, when the current profile was deliberately contracted, the temperature profile was also contracted and sharply peaked even during tlie earliest phase of the discharge (see Fig. 7). Furthermore, during the quasisteady phase of this discharge, the electron temperature was greater (both volume-averaged and peak), the ohmic input power was less, and thus the electron energy confinement time, 'Ee' was greater as shown in Fig. 8. $\tau_{E e}$ is defined as the electron energy divided by the ohmic input power where the electron energy is calculated from the Thomson ssattering measurements. The improvement in electron energy confinement time during the quasi-steady state does not appear to be due primarily to changes $\therefore$ ine radiation from the core of the discharge. In Fig. 9, the total energy stored in the discharge within a radius $r$, the integrated ohmic input, and the bolometric power radiated are shown. To evaluate the energy stored in the discharge, the ion energy is calculated self-consistently assuning neoolassical ion heat conductivity and including convection, charge exchange and electron-ion collisions, and added to the electron energy. For the conditions of these experiments, the electrons and ions are relatively well equilibrated snd the uncertainty which this model introduces into 
the calculation of the energy stored in the discharge is less than 10\%. The bolometric measurements of the flux of power out of the discharge, including both charge exchange and radiation, were Abel inverted assuming that the power is predominately due to radiation. Figure 9 also shows the energy transport time defined by

$$
\tau_{E}^{T}(x)=\frac{\frac{3}{2} \int_{0}^{x}\left(n_{e} k T_{e}+n_{i} k T_{i}\right) r d r}{\int\left(p_{O H}-p_{r a d}\right) r d r},
$$

as well as the more usual energy confinement time defined by

$$
\tau_{E}(x)=\frac{\frac{3}{2} \int_{0}^{r}\left(n_{e} k T_{e}+n_{i} k T_{i}\right) r d r}{\int_{0}^{r} p_{C} r d x}
$$

where $\mathrm{P}_{\mathrm{OH}}$ and $\mathrm{p}_{\mathrm{rad}}$ are the local ohmic input power and bolometric radiated power respectively. The two discharges differ in stored energy and in ohmic input power; the latter reflecting a change in the one turn loop voltage since the plasma currents are nearly the same. In neither discharge is the power radiated from the plasma core $(x \leq 10 \mathrm{~cm})$ the dominant power loss term. Within the plasma core both discharges exhibit similar values of ${ }^{\tau} E$ and $T_{E}^{T}$ (although in the contracted discharge small internal disruptions observed in the soft $x$-ray emission might have affected the confinement), but outside the core both $\tau_{E}$ and $\tau_{E}^{m}$ are about twice as long in the contracted discharge. Thus, the increase in the quasi-steady state energy confinement time which accompanies the contraction of the current channel during startup is due to a reduction in plasma transport. 
The electron heat conductivity was evaluated with the assumption that the power flow from the electrons to the ions can be calculated with the model used to evaluate the ion temperature and also including the ohmic input power, the bolometric radiated power and an estimate of convection. The electron heat conductivity, $k$, was found to decrease by a factor of about two in the discharge which was contracted. This is partly a result of the difference in the electron temperature gradient scale length. The analysis of $k$ is more sensitive to the uncertainties in the ion heat transport model than the calculation of $\tau^{T}$, which is quite insensitive.

3.2 Contracting the current profile through intense gas bursts

The electron energy confinement time can also be improved by contracting the current profile later in the discharge with short (100 and $120 \mathrm{msec}$ ) though intense (10 to 30 Torr $-1 / \mathrm{sec}$ ) gas bursts, as shown in Fig. 10. In this experiment, biie flow of gas was controlled directly and the gas valve was not part of a feedback loop. The effect of these gas bursts is again to contract the current channel, perhaps by inducing a minor disruption. During the bursts, the strength of the CIII emission increases very substantially (factor of $\sim 20$ ), as does the emission from other low ionization states of carbon and oxygen (OVI, CIV). However, the 
emissil.. from the higher ionization states - CV, CVI, and OVII either remains the same or decreases slightly. The behavior of these lines is qualitatively similar to changes in emission observed on the ATC tokamak during rf heating [10]. The analysis of the ATC data indicated that a substantial increase in particle recycling in the plasma periphery was required to account for these changes $[10,20]$. Profile changes of the electron density and temperature sannot in either experiment fully account for the observed increase in the emission of the lower ionization states. Furthermore, in the PLT experiment, emission of hydrogen light also was increased substantially (factor of $\sim 20$ ) which is a direct indication of the decreased particle replacement time in the plasma periphery.

The enhanced particle recycling indicates a mechanism by which the power balance in the periphery can be substantiajly altered, thus modifying the temperature profile. In all of the experiments discussed in this paper, the power loss by ionization of the gas influx through the valve is negligible compared with the ohmic input Eower, so that this gas influx cannot directly affect the power balance in the plasma periphery and contract the current profile. However, if the gas influx induces rapid recycling of both the background gas and low z impurities in the plasma periphery, then the power balance there can be altered and as a result the overall current and temperature profile can change. The importance of this mechanism in contracting the current profile in the other experiments discussed in this paper has not been determined. 
After the gas bursts (after $~ 500$ msec in Fig. 10) the energy replacement time increased substantially. Figure 11 shows the electron temperature and density profile of the discharge shown in Fig. 10 evaluated after the gas bursts and the corresponding plasma parameters. The electron and ions are even better equilibrated than in the discharge shown in Fig. 8, so that the total energy replacement time is $\approx 100 \mathrm{msec}$.

In Fig. 12 the electron energy confinement time in the discharges in which the current profile was deliberatly contracted is compared with a more usual sample of data. Titanium gettering was used with either carbon or steel limiters. The usual sample of data includes both types of discharges - those which were and were not contracted. By deliberately contracting the profile, the longest electron energy confinement times for a given density have been attained. A further inaication that the variation in confinement time cannot be attributed to differences in high $\mathbf{z}$ impurities alone is that both carbon and stainless steel limiters show a similar variation in confinement time for the same density. In discharges with carbon limiters, the level of iron radiation is typically a third or so of what it is wiṭ stainless steel limiters. Furthermore, bolometric and spectroscopic measurements indicate that in gettered ohmically heated discharges with either carbon or stainless steel limiters, radiation for the core is not the dominant power loss mechanism in the quasi-steady state.

\section{SUMMARY}

The results of PLT experiments conducted with various limiters indicate the importance of carefully controlling the gas influx. 
By adjusting the gas influx, it is fossible to decrease plasmalimiter interaction and the influx of high $z$ impurities from either stainless steel or tungsten limiters and also to improve the energy confinement time. The mechanism by which the gas influx alters both the evolution of the discharge as well as the conditions in the periphery is rather subtle. As pointed out, the power loss due to ionization of the gas is small comparer to the ohmic heating power. Thus, the gas influx appears to act indirectly in altering the profile of the discharge. It appears that just as it was important to develop techniques to control the macroscopic properties of the discharge (for instance, discharge cleaning, titanium gettering, limiter design), it is now necessary to develop further and to implement new techniques aimed at profile control, in order to minimize the high $\mathrm{z}$ impurity influx, and optimize both the temperature and nt of the discharge. Controlling the gas influx, though perhaps the simplest, is only one of several techniques w. ich can be used and all of which need to be studied further.

\section{ACKNOWLEDGMENTS}

W. Jish to acknowledge the support given this work by $W$. Stodiek and by J. A. Schmidt. This work was supported by the United States Department of Energy Contract No. EY-76-C-02-3073.

\section{REFERENCES}

[1] GORBUNOV, E. P., MIRNOV, S. V., STRELKOV, V. S., Nucl. Fusion $10(1970), 43$; also MIRnov, s. V., Conf. Plasma Physics and Controlled Nuclear Fusion Research paper, IAEA-CN-37-F-1-2 
[2] BOROVSKI.T, G. A., KU?.NETSOV, E. I., RAZUMOVA, K. A., SOV. Phys. J.E.T.P., 32, $(1971), 599$.

[3] DAUGHreY, C. C., Nucl. Furion 16, 1976, 1045 also see DAUGHNEY, C. C., Princeton Plasma Phys. Lab. Report 1442, (1978).

[4] JASSBY, D. I., COHN, D. R., PARKER, R. R., Nucl. Fusion 16, (1976) 1045, also see GONDHALEKAR, A., et al., Conf. Plasma Physics and Controlled Nuclear Fusion Research Paper, IAEACN-37-C-4 (1978).

[5] MURAKAMI, M., CALLEN, J. D., BERRY, L. A., Nucl. Fusion 16, (1976) 347, and also, MURAKAMAI, M., Bu1l. Am. Phys. Soc. paper 1A7, (1978).

[6] HUGILI, J. SHEFFIELD, J., Nucl. Fusion 18, (1978) 15, and also PFEIFFER, W. W., WALTZ, R. E., GA-A14727 (1978) to be published.

[7] MESERVEY, E. B., BRETZ, N., DIMOCK, D. L., and HINNOV, E., Nucl. Fusion 16, (1976) 593.

[8] BOI, K., et al., Conf. Plasma Physics and Controlled Nuclear Fusion Research Paper IAEA-CN-37-A-1 (1978).

[9] HINNOV, E., SUCKEWER, S., BOI, R., HAWRYLUK, R. J., HOSEA, J., MESERVEY, F., Plasma Physics 20, (197.8) 723.

[I0] SUCKEWER, S., HAWRYLUK, R. J., Phys, Rev. Lett. 40, (1978), 1649.

[11] OREN, I.. TAYLOR, R. J., Nucl. Fusion 17, (1977), 1143.

[12] ARUNASALAM, V., et al., Proc. Eight European Conference on Controlled Fusion and Plasma Physics, Prague, Vol. 2 p. 17 (1977) to be published in Nucl. Fusion also Princeton Plasma Physics Laboratory Report 1436 (1978).

[13] HSUAN, H., et al., Proc. Joint Varenna and Grenoble Int'I. symp. on Heating in Toroidal Plasma, Grenoble 2 , (1978), 87. 
[14] VON GOELER, S., SAUTHOFF, N., BITTER, M., et al., PPPL-1383 (1977) .

[15] HINNOV, E., BOL, K., DIMOCK, D., HAWRYLUK, R. J., JOHNSON, D., MATTIOLI, M., MESERVEY, E., VON GOELER, S., NuCl. Fusion 18, (1978), 1305 .

[16] MUKHOVATOV, V.S., SHAFRANOV, V. D., Nual, Fusion 21, (1971) 605 .

[17] STOTT, P. E., DAUGHNEY, C. C., ELLIS, R. A., JR., Nucl. Fusion 15. (1975), 431 .

[18] FIELDING, S. J., et al,, Nucl. Fusion 17, (1977) 1382.

[19] BRETZ, N., DIMOCK, D., FOOTE, V., JOHNSON, D., LONG, D., TOLNAS, E., Appl. Optics 17, (1978) 192.

[20] HAWRYLUK, R. J., SUCKEWER, S., HIRSHMAN, S. P., Princeton Plasma Physics Laboratory 1473 (1978) to be published in Nuclear Fusion. 


\section{EIGURE CAPTIONS}

Fig. 1. Comparison of two hydrogen discharges with tungsten limiters. Both the initial filling pressure and the gas influx rate were increased in the discharge labeled (b) compared with (a).

Fig. 2. Tungsten radiation (ultra-soft $x$-ray detector) versus the current profile shape $\left(\ell_{i} / 2+\beta_{\theta}\right)$ evaluated at $70 \mathrm{msec}$ into the discharge.

Fig. 3. Current profile $\left(\ell_{i} / 2+\beta_{\theta}\right)$ versus electron density evaluated at $70 \mathrm{msec}$ into the discharge. The discharges shown here are a subset of Fig. 2 in which the initial ohmic heating current was kept constant.

Fig. 4 (a) Schematic illustration of the change in the carbon limitex temperature with time. (b) Change in the carbon liniter temperaturc as a function of the current profile shape $\left(R_{i} / 2+\beta_{\theta}\right)$.

Fig. 5. Gas feedback system used to operate the pulsed gas valve and control the density and $\ell_{i} / 2+\beta_{\theta}$ waveform. The difference between the measured and preprogrammed signal is exaggerated for clarity.

Fig. 6. Comparison of two deuterium discharges using the gas feedback system. In the october 16, 1978 (dotted line) only the density input was used while in the October 24 , 1978 (solid line), both the density and $\ell_{i} / 2+B_{\theta}$ were used to contract the current profile.

Fig. 7. Comparison of the evaluation of the temperature profile for the discharges shown in Fig. 6 .

Fig, 8. Thomson scattering profiles in the quasi-steady state comparing the two discharges shown in Fig. 6. 
Fig. 9. Comparison of the energy ( $E_{1}$, integrated ohmic input power $\left(\mathrm{P}_{\mathrm{OH}}\right)$, bolometric power radiated $\left(\mathrm{P}_{\mathrm{rad}}\right)$, energy transport time $\left(\mathrm{r}^{\mathrm{T}}\right)$ and energy replacement time $\tau_{E}(r)$ for the two discharges shown in Fig. 8 .

Fig. 10a. Line average density based upon the 2 microwave interferometer and Thomson scattering measurements and the duration of the intense gas bursts used to increase the density and contract the current profile. (b) Line emission of CIII radiation versus time.

Fig. 11a. Thomson scattering profiles of the discharges shown in Fig. 10 arter the intense gas bursts. Values for $z_{\text {eff }}$ slightly less than one are encountered frequently in high density discharges and we cannot account for the difference through experimental error. The cause of this effect is unknown. The value obtained without including the neoclassical corrections is 1.2 .

Fig. 12. Electron energy replacement time versus density. The black circles and crosses correspond to the two experiments discussed in the text in which the current profile was deliberately contracted. The open circles and triangles are a typical sample of data using stainless steel and carbon limiters respeatively with titanium gettering. 

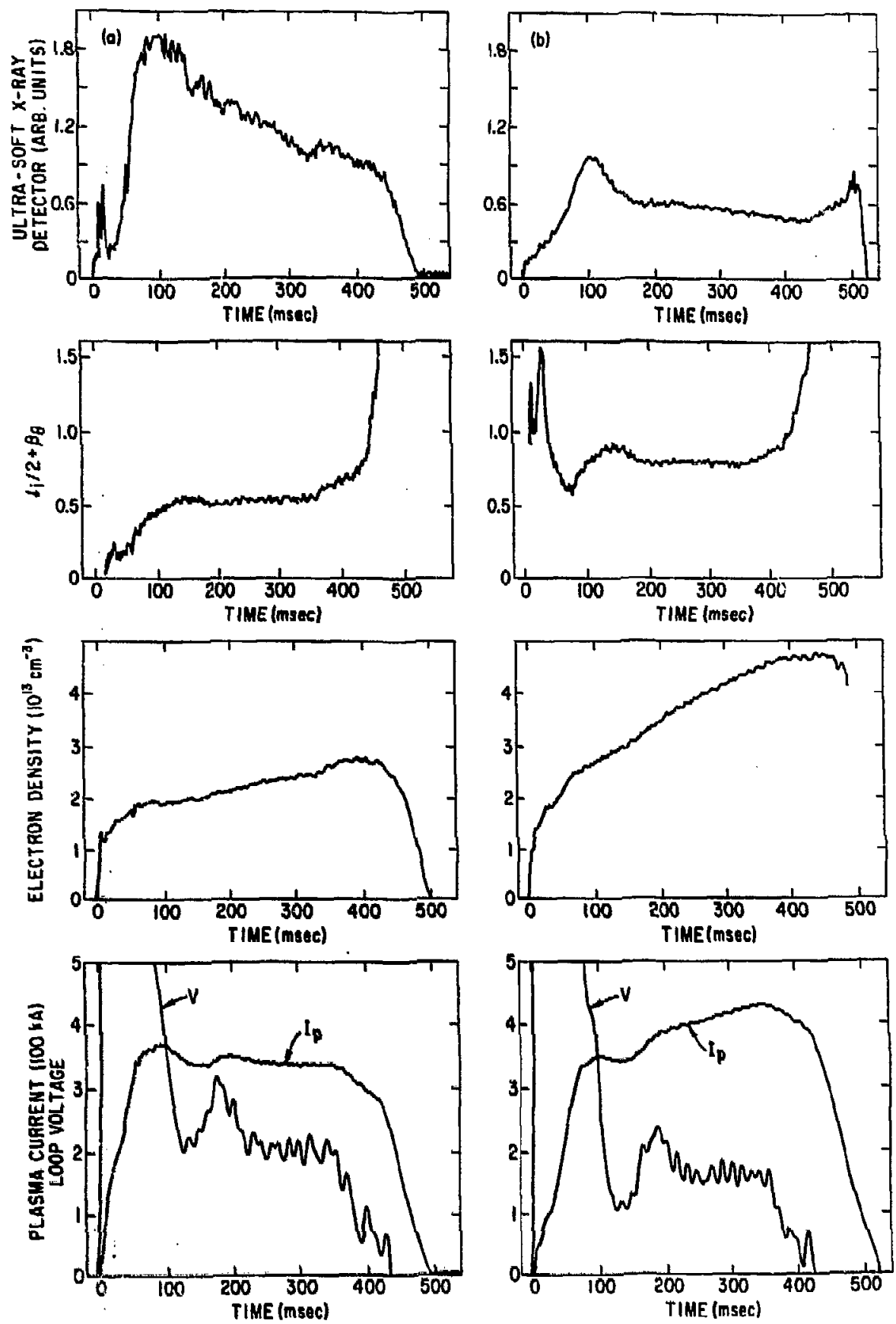

Fig. 1. 793179 


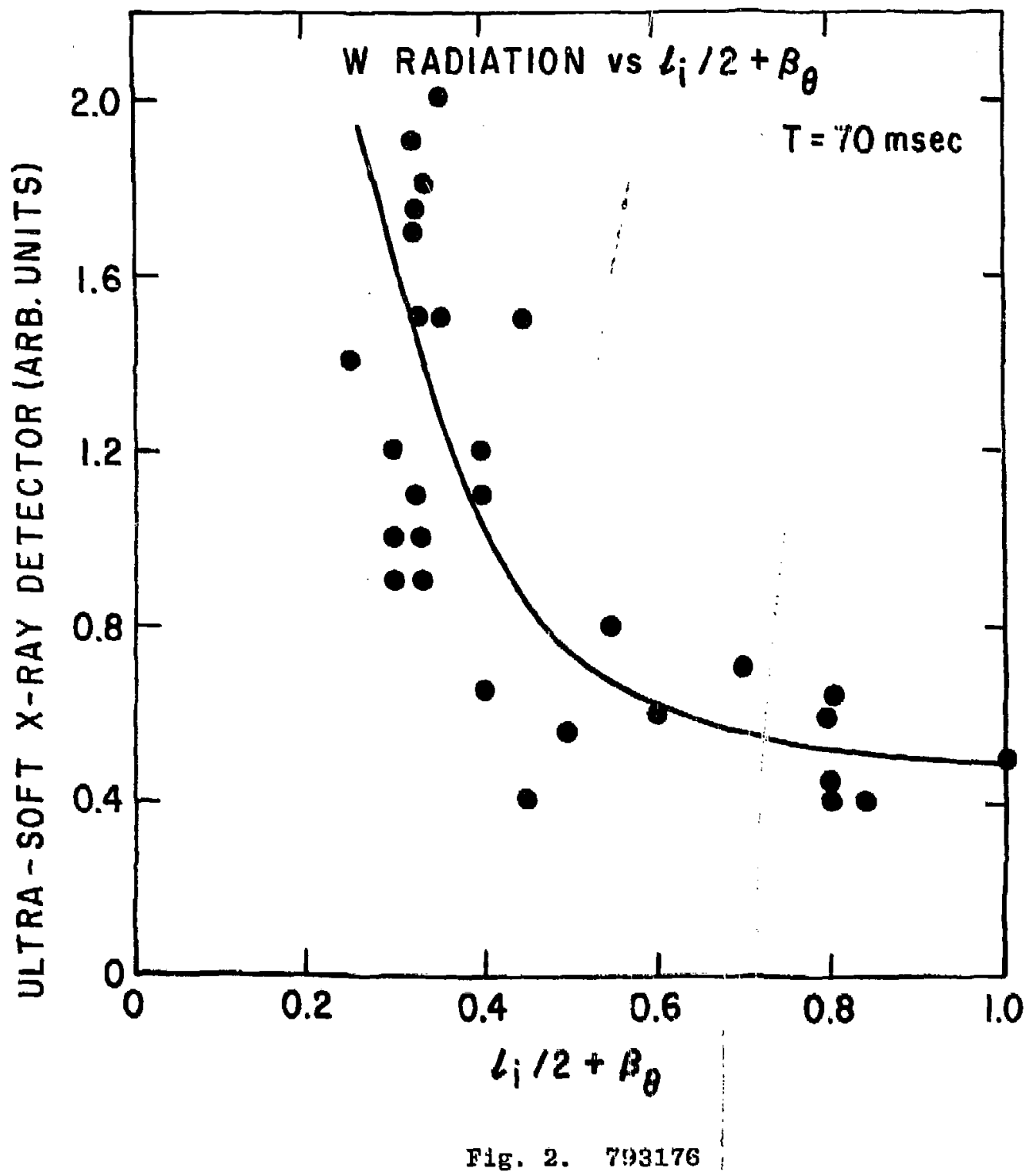




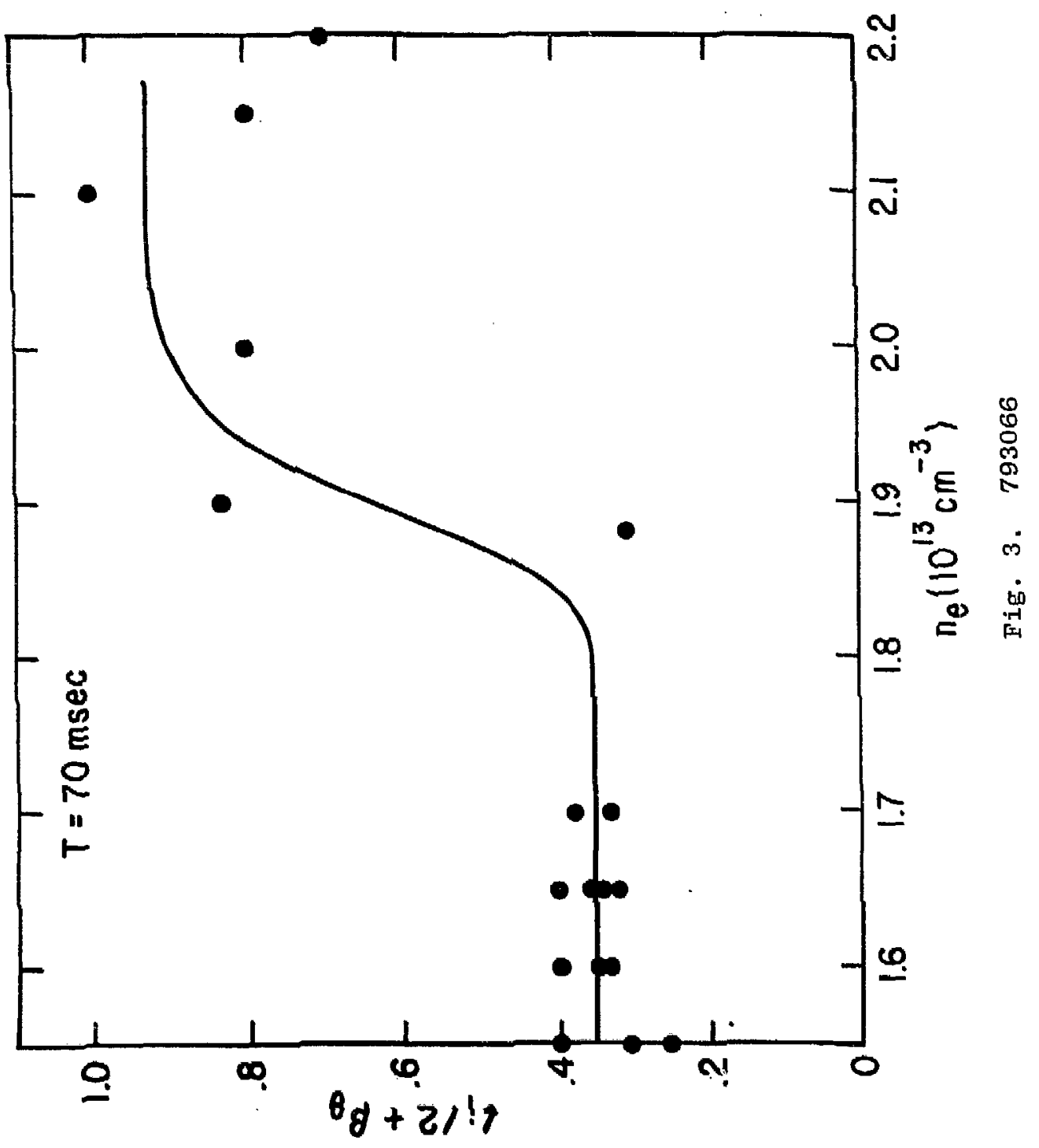



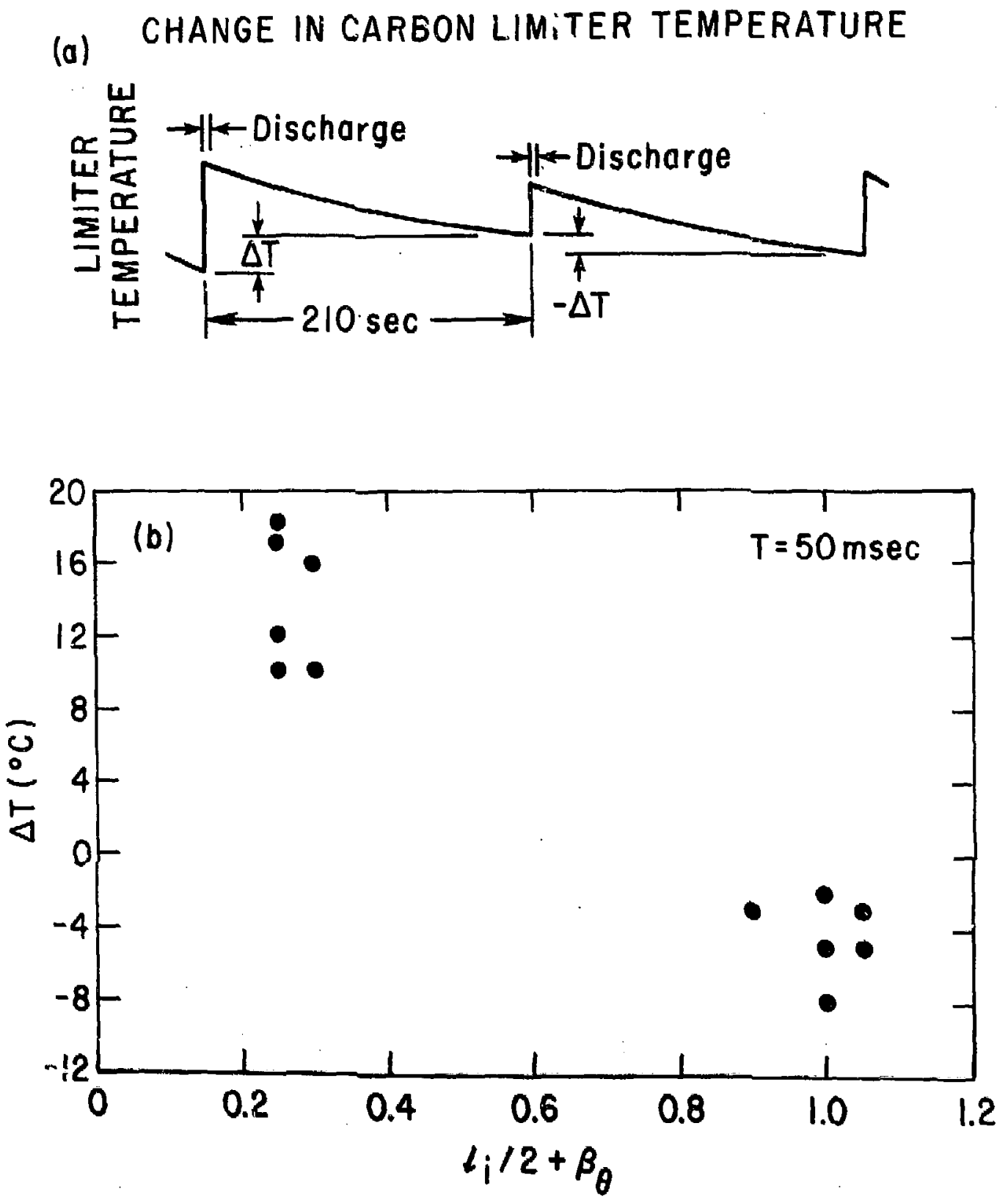

Fig. 4. 793231 
PLT GAS FEEDBACK SYSTEM
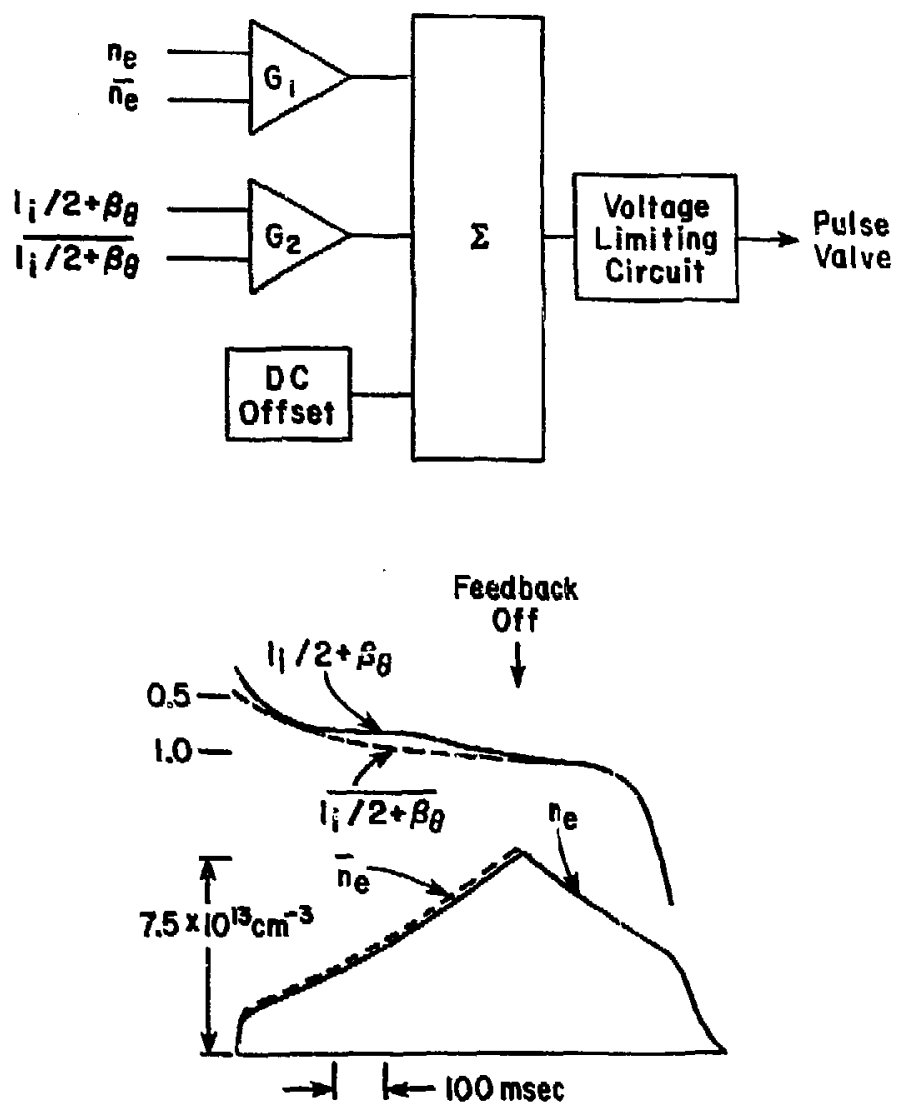

HIGH DENSITY
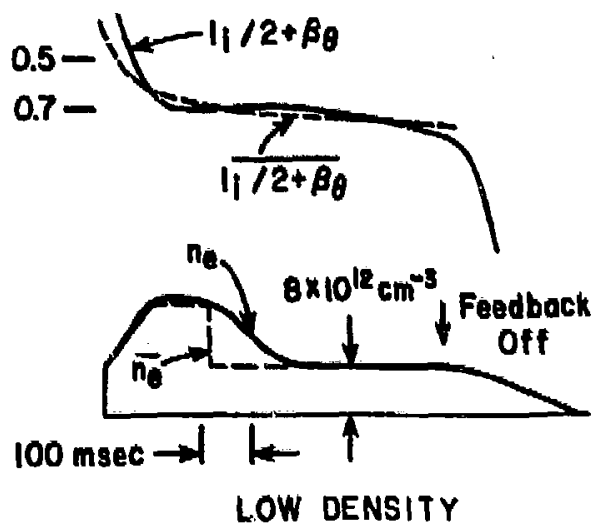

Fig. 5. 793177 

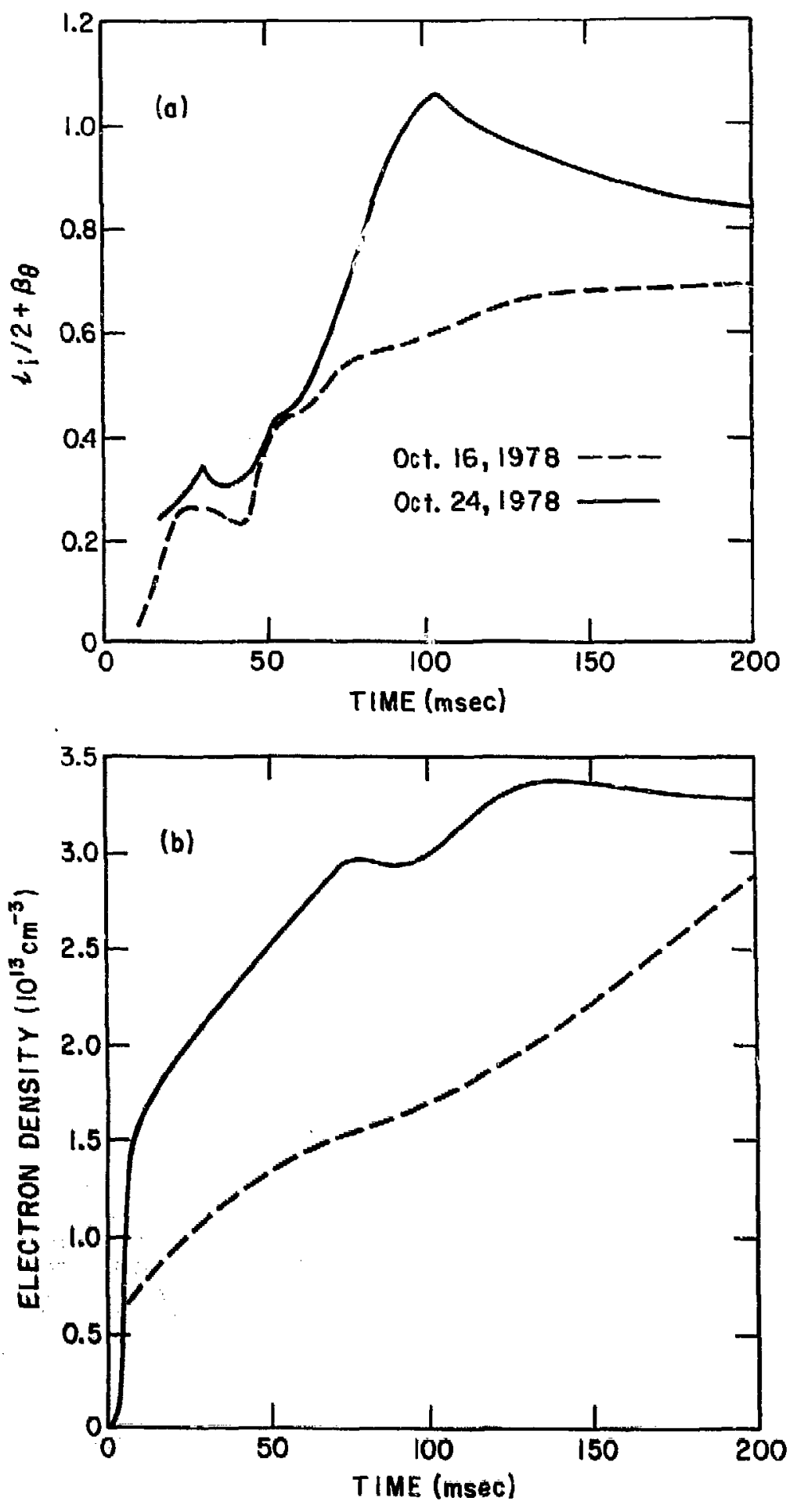

Fig. 6. 793025 

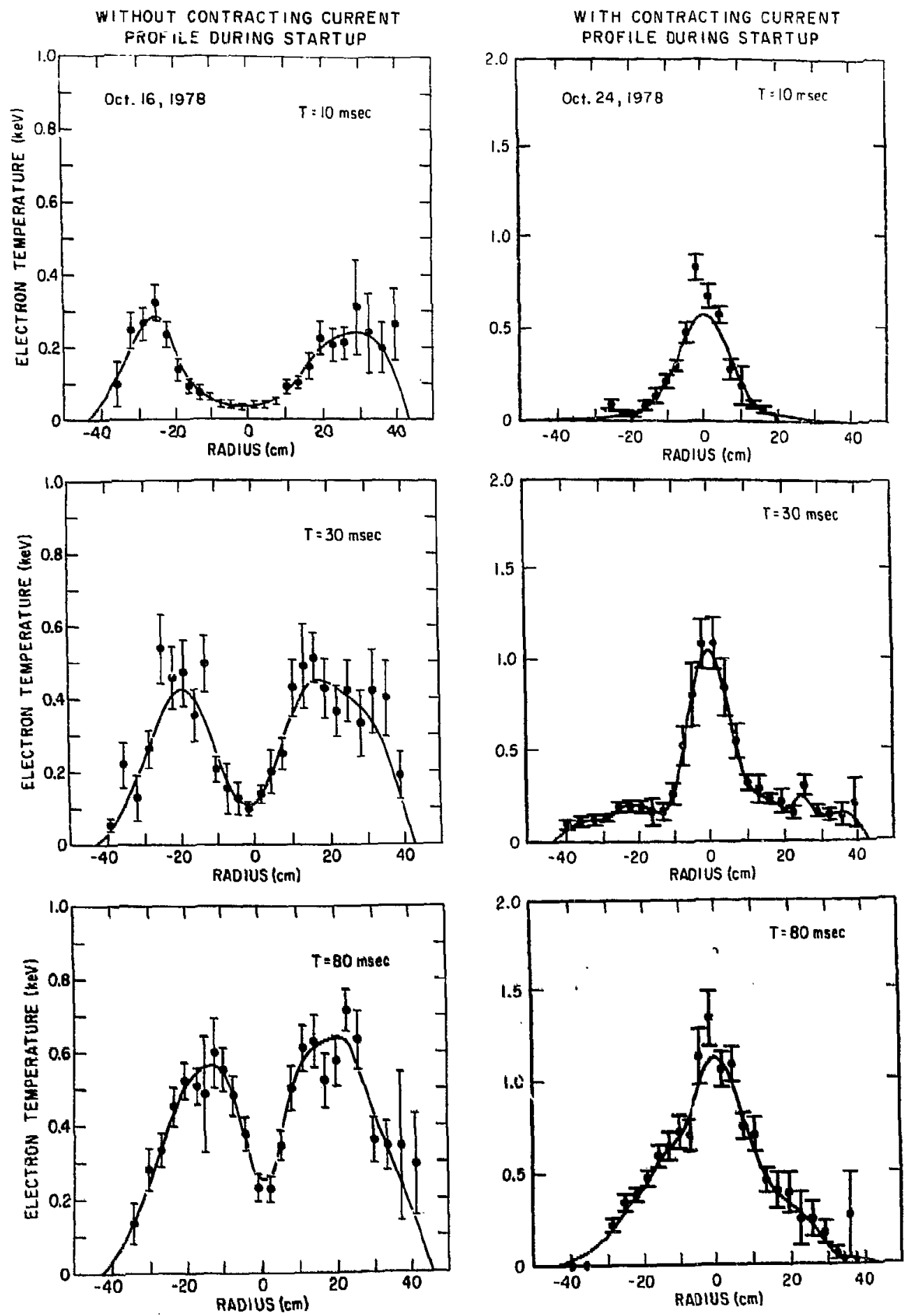

Fig. 7. 793178 


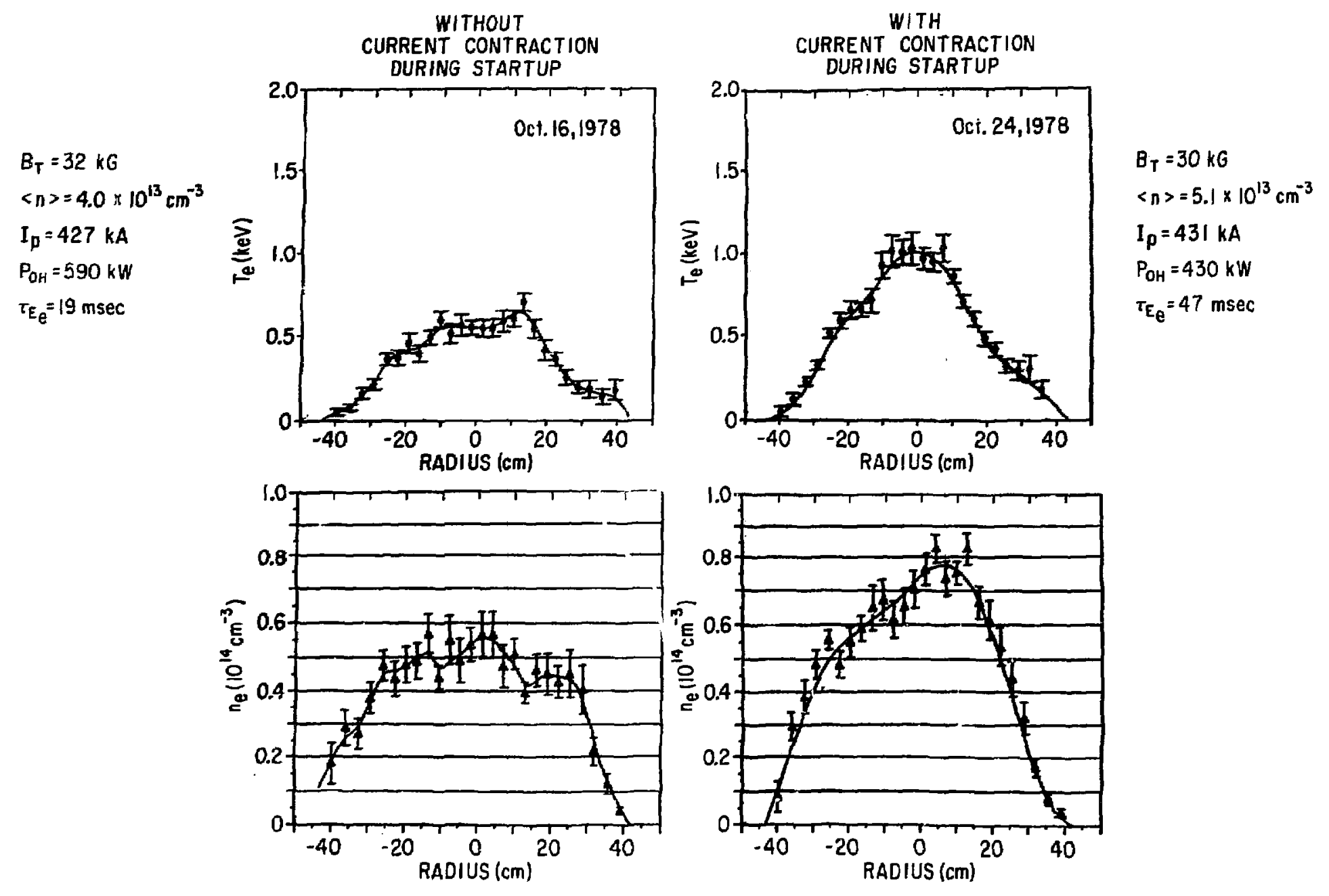

Fig. $3 . \quad 793067$ 


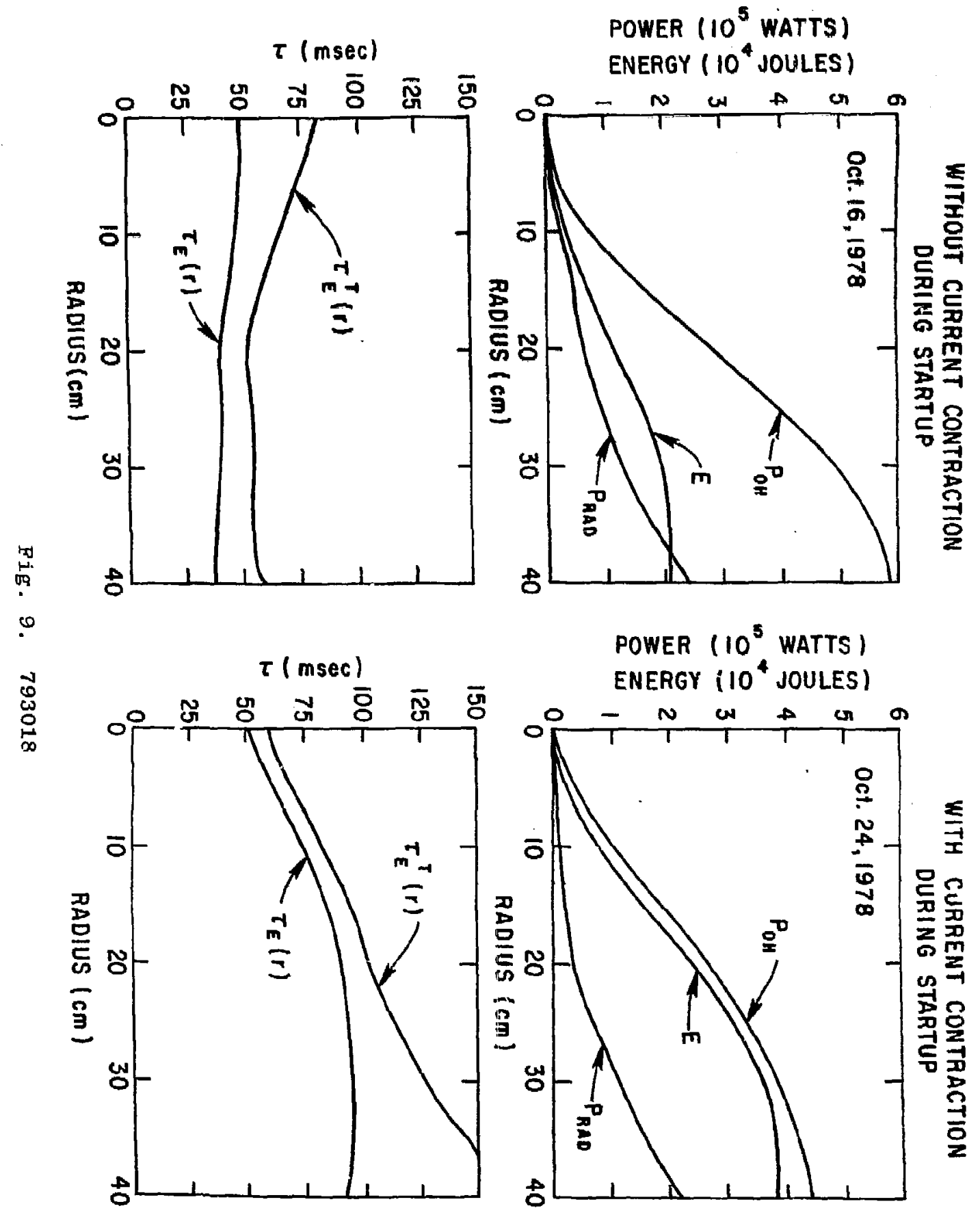



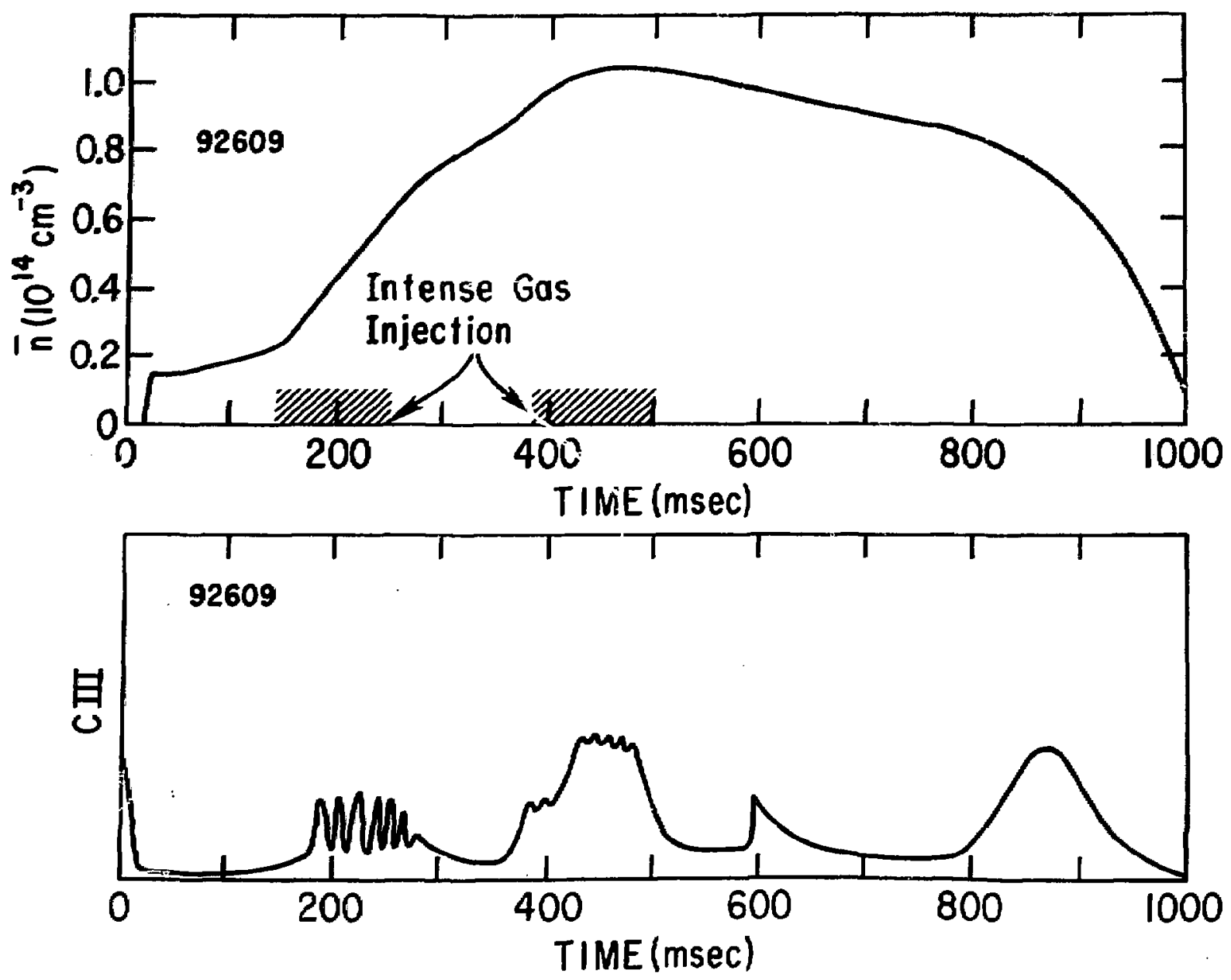

Fig. 10. 793180 
$t=700 \mathrm{~ms}$

$\bar{n}=0.92 \times 10^{14} \mathrm{~cm}^{-3}$

$B_{T F}=32 k G$

$\mathrm{I}_{\mathrm{p}}=470 \mathrm{kA}$

$V=1.1 \mathrm{~V}$

$\left\langle T_{e}\right\rangle=0.41 \mathrm{keV}$

$Z_{\text {eff }}=0.9$

$\tau_{E_{e}}=52.5 \mathrm{~ms}$
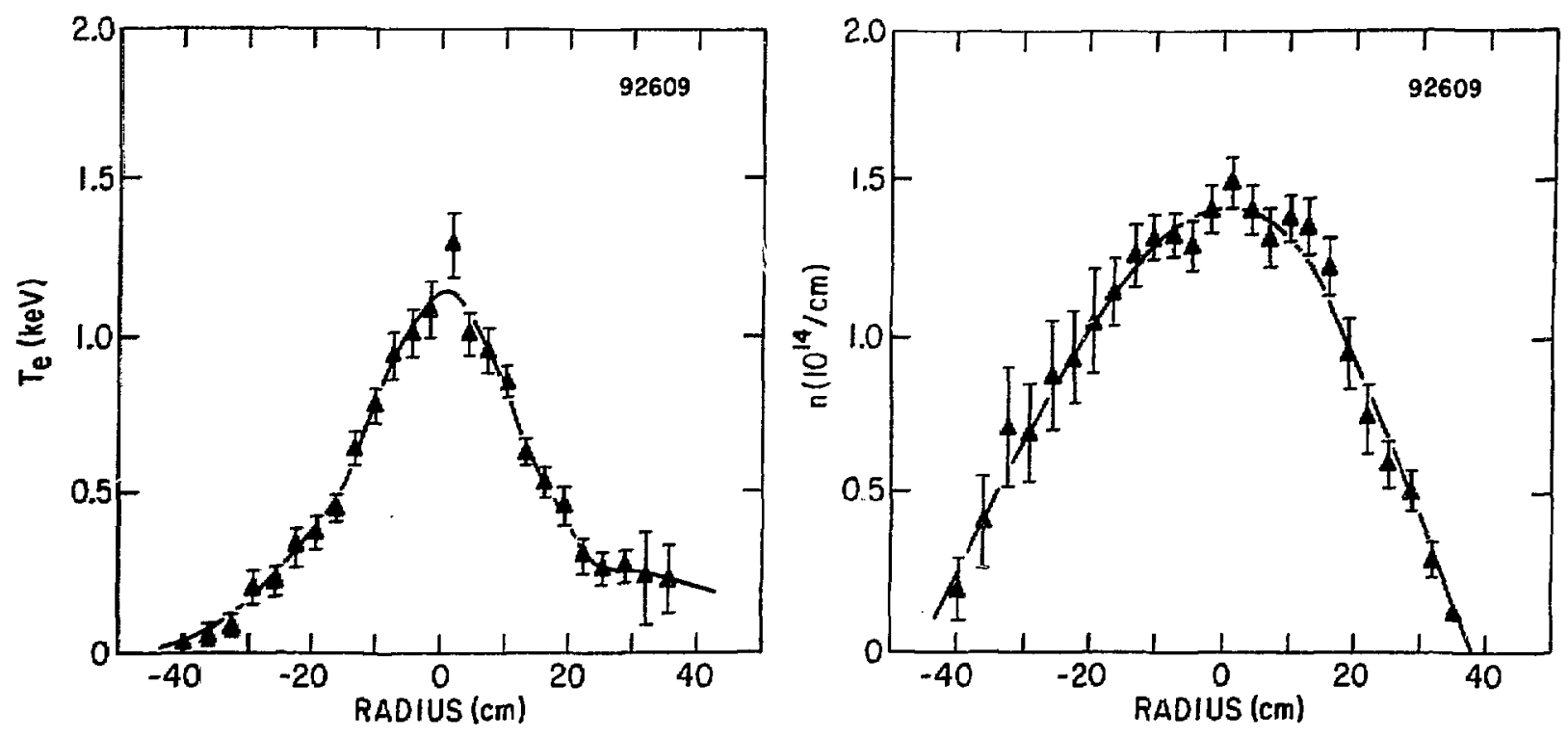

Fig. 11. 793246 


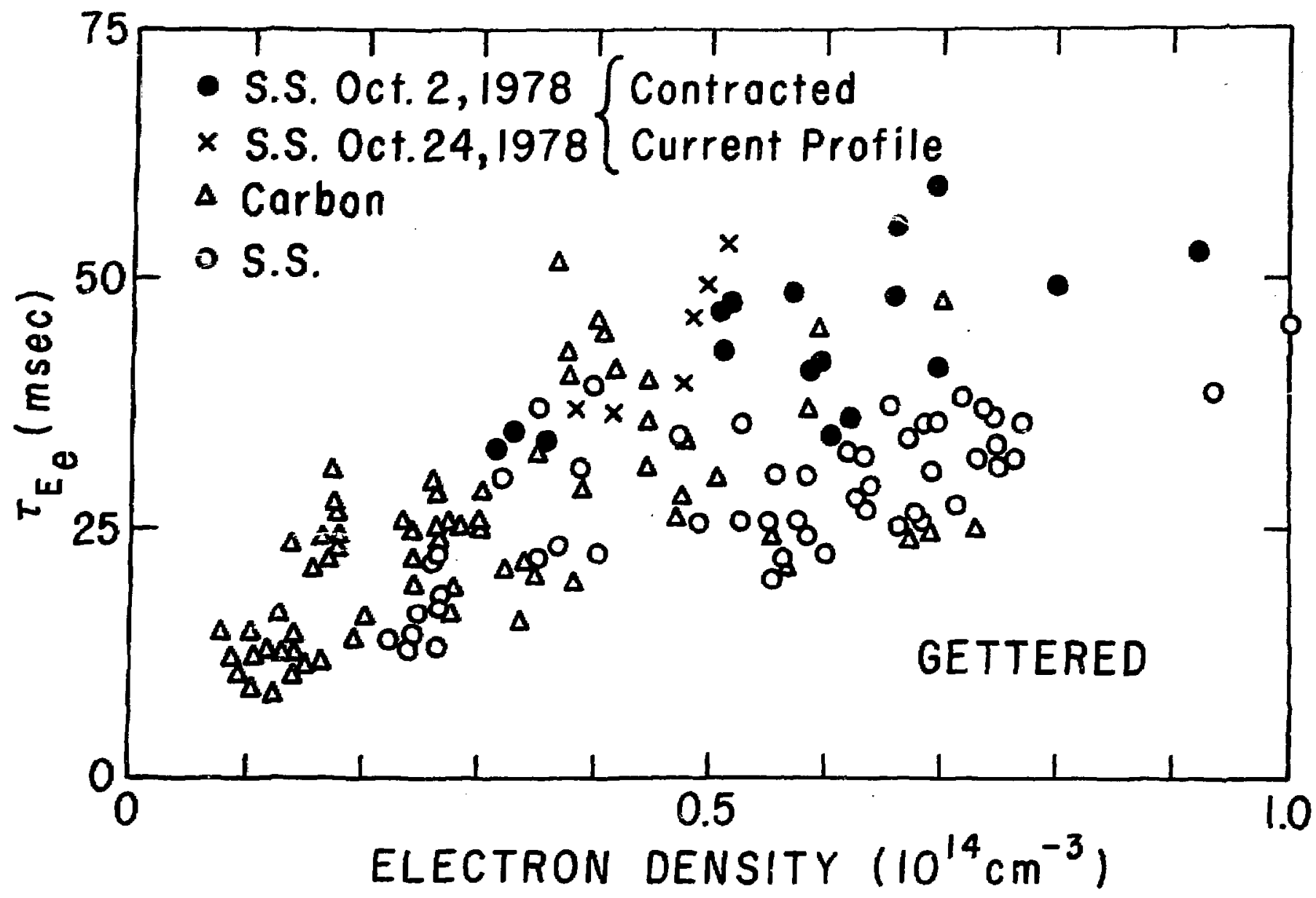

Fig. 12. 793017 


\section{ALL C:NTEGIORIES}

R. Askew, Auburn University, Alabama

5. T. Wu, Univ. of Alabama

Leophysical institute, Univ. of Alaska

G.L. Jolnston, Sonorna State Univ, California

H. H. Kuehl, Univ. of S. California

Institute for Energy Studies, Stanford University

H. D. Campoell, University of Florida

N. L. Oleson, University of South Florida

W. M. Stacey, Georgia Institute of Technology

Benjarnin Ma, lowa State University

Nlagne Kristiansen, Texas Tech. University

W. L. Wiese, Nat'l Bureau of Standards, Wash., D.C.

Australian National University, Canberra

C.N. Watson-Munro, Univ. of Sydney, Australia

F. Cap, Inst. for Theo. Physics, Austria

Ecole Royale Militaire, Bruxelles, Belgium

1). Palumbo, C. European Cornm. B-1049-Brussels

P.H. Sakanaka, Instituto de Fisica, Campinas, Brazil

C. R. James, University of Alberta, Canada

T.W. Johnston, INRS-Energie, Vareenes, Quebec

H. M. Skarsgard, Univ, ol Suskatchewan, Canada

Librarian, Culham Laboratory, Abingdon, England

A.M. Dupas Library, C.E.N.-G, Grenoble, France

Central Res. Inst. for Physics, Hungary

R. Shingal, Meerut College, India

A.K. Sundaram, Phys. Re5, Lab., India

il. Naraghi, Atornic Energy Org. of Iran

Biblioteca, Frascati, Italy

Biblioteca, Milano, Italy

i. Rostagni, Univ. Di Padova, Padova, Italy

Preprint Libr.iy, Inst. de Fisica, Pisa, Italy

Library, Plasma Physics Lab., Gokasho, Uji, Japan

5. Nori, Japan Atomic Energy Res. Inst., Tokai-Mura

Research Infor mation Center, Nagoya Univ., Japan

5. Shioda, Tokyo Inst, of Tech.,Japan

inst. of Space \& Aero. Sci., Univ. of Tokyo

T. Uchida, Univ. of Tokyo, Japan

H. Yamato, Toshiba R. \& D. Center, Japan

v. Yoshikawa, JAERI, Tokai Res. Est., Japan

V. Yajima, Kyustu Univ., Japan

R. England, Univ. Nacional Auto-noma de Mexico

13. S. Liley, Univ. of Waikato, New Zealand

5. A. Moss, Saab Univas Norge, Norway

1.A.C. Cabral, Univ. de Lisboa, Portugal

O. Petrus, AL.I. CUZA Univ., Romania

3. de Villjers, Atomic Energy Bd., South Africa

A. Naurech, Comisaria De La Energy y Recoursos Minerales, Spain

Library, Royal institute of Technology, Sweden

Cen. de Res. En Phys.Des Plasmas,Switzerland

Librarian, Fom-Instituut Voor Plasma-Fysica, The Netherlands

V. E. Golant, A.F. Ioffe Physical-Tech. Inst.,USSR

B.B. Kadomtsev, Kurchatov Inst. of Atomic Energy, USSR

The Kharkov Physical-Tech, Inst., USSR

M. S. Rabinovich, Academy of Sci, USSR
Bibliothek, Stuttgart, West Germany

R.i). Buhler, Univ. of Stuttgart, West Germatiy

Max-Planck-Inst. fur Plasmaphysik, W. Germany

Nucl. Res. Estab., Julich, West Germany

K. Schindler, Inst. Fur Theo. Physik, W. Germany

\section{EXPERIMENTAL THEORETICAL}

M. H. Brennan, Flinders Univ. Australia

H. Barnard, Univ. of British Columbia, Canada

S. Screenivasan, Univ, of Calgary, Canada

J. Radet, C.E.N.-B.P., Fontenay-aux-Roses, France

Prof. Schatzman, Observatoire de Nice, France

5. C. Sharma, Univ. of Cape Coast, Ghana

R. N. Aiyer, Laser Section, India

B. Buti, Physical Res. Lab., Indiz

L. K. Chavda, S. Gujarat Univ., India

I.M. Las Das, Banaras Hindu Univ., Inctia

5. Cuperman, Tel Aviv Univ., Israel

E. Greenspan, Nuc. Res. Center, Israe

P. Rosenau, Israel I'nst. of Tech., Israe'

Int'l. Center for Theo. Physics, Trieste, Italy

I. Kawakami, Nihon University, Japan

T. Nakayama, Ritsumeikan Univ., Japan

S. Nagac, Tohoku Univ., Japan

3.t. Sakai, Toyama Univ., Japan

S. Tjotta, Univ, I Bergen, Norway

M.A. Hellberg, Univ. of Natal, South Africa

H. Wilhelmson, Chalmers Univ. of Tech., Sweden

Astro. Inst., Sonnenborgh Obs., The Netlerlands

N.G. Tsintsadze, Academy of Sici GSSR, USSR

T. J. Boyd, Univ. College of Narth Wales

K. Hubner, Univ, Heidelberg, W.Germany

H. J. Kaeppeler, Univ. ol Stut tgart, West Germany

K. H. Spatschek, Univ. Essen, West Germany

\section{EXPERIMENTAL ENGINEERING}

B. Grek, Univ. du Quebec, Canada

P. Lukac, Komenskeho Univ., Czechoslovaikia

G. Hor ikoshi, Nat'l Lab for High Energy Physics, Tsukuba-Gun, Japan

V. A. Glukhikh, D.V. Efremoy Sci. Res. Instit. of Elect. App., USSR

\section{EXPERIMENTAL}

F. J. Paoloni, Uniy. of Wollongong, Australia

J. Kistemaker, Fom Inst. for Atomic \& Molec. Physics, The Netherlane's

\section{THEORETICAL}

F. Verheest, Inst. Vor Theo. Mech., Bulgium

J. Teichmann, Univ. of Montreal, Car.ada

T. Kahan, Univ, Paris VII, France

R. K. Chhajlani, India

S. K. Trehan, Panjab Univ., India

T. Namikawa, Osaka City Univ., Japan

H. Narumi, Univ, of Hiroshima, Japan

Korea Atomic Energy Res. Inst., Korea

E. T. Karlson, Uppsala Univ., Sweden

L. Stenflo, Univ. of UMEA, Sweden

7. R. Saraf, New Univ., United Kingd.om 